\title{
Social Prescribing for Individuals Living with Mental Illness in an Australian Community Setting: A Pilot Study
}

\author{
Christina Aggar $^{1} \cdot$ Tamsin Thomas $^{1} \cdot$ Christopher Gordon ${ }^{2} \cdot$ Jacqueline Bloomfield $^{2} \cdot$ James Baker $^{3}$
}

Received: 27 August 2019 / Accepted: 5 May 2020 / Published online: 13 May 2020

(c) The Author(s) 2020

\begin{abstract}
Social prescribing, also known as "community referral", is a means of referring individuals living in the community to existing local non-clinical health, welfare, and social support services. International evidence demonstrates that social prescribing improves biopsychosocial quality of life, and burden on health services. Australia's first social prescribing pilot program for individuals with mental illness (mood and psychotic spectrum disorders) was implemented in Sydney in 2016/2017; this study evaluates that program. Participants included 13 adults who were assessed at baseline and six-month follow-up. Outcomes included self-perceived quality of life, welfare needs, health status, loneliness, social participation, and economic participation. Results indicate significant improvements in quality of life and health status. This pilot program demonstrates that social prescribing may improve participant outcomes. It fits well within Australian health policy and funding models which focus on bolstering community care, and may be scalable, particularly in geographically isolated communities.
\end{abstract}

Keywords Behavioural health $\cdot$ Case management $\cdot$ Community healthcare

$\begin{array}{ll}\text { Abbreviations } \\ \text { CANSAS } & \begin{array}{l}\text { Camberwell Assessment of Need Short } \\ \text { Appraisal Schedule }\end{array} \\ \text { ED } & \text { Emergency Department } \\ \text { EQ5D } & \text { EuroQol Health Thermometer } \\ \text { GP } & \text { General Practitioner } \\ \text { K10 } & \text { Kessler Psychological Distress Scale } \\ \text { QoL } & \text { Quality of Life } \\ \text { UCLA } & \text { University of California, Los Angeles } \\ \text { WHO-QoL } & \text { World Health Organisation Quality of Life }\end{array}$

Christina Aggar

Christina.Aggar@scu.edu.au

1 School of Health and Human Sciences, Southern Cross University, Gold Coast campus, room B7.15, Southern Cross Drive, Bilinga, QLD 4225, Australia

2 Susan Wakil School of Nursing and Midwifery, Faculty of Medicine and Health, The University of Sydney, Sydney, NSW 2006, Australia

3 Primary and Community Care Services, Unit 7, 1 Central Avenue, Thornleigh, NSW 2120, Australia

\section{Introduction}

Mental illness impacts individuals and the wider community and places a considerable financial burden on the health system (AIHW 2016). Mental illness is affected by biological, psychological, and social factors, and treatments targeting a range of these factors, including the wider determinants of health, are more likely to be effective (WHO 2005). Social prescribing programs address these biopsychosocial factors via care coordination and linkage where individuals with mental illness are referred to local community-based social care services and structured social activities (Knapp et al. 2012). These services can be public, private, or volunteer services, and address a broad range of needs across biopsychosocial domains including physical health (medication management, disease-specific groups, diet, exercise), psychological health (support groups, counselling), welfare (food, housing, employment), and social support (group activities, befriending services).

Social prescribing for mental illness may have a role to play in the Australian contact as, in Australia, mental illness is experienced by approximately $45 \%$ of people aged 16-85 years during their lifetime, and $20 \%$ of the population experience mental illness each year (ABS 2008). Mental illness accounts for $12 \%$ of the total burden of disease and $23.6 \%$ of the non-fatal burden of disease (AIHW 2016). 
Between 2014 and 2015, Australian mental health service spending was approximately $\$ 8.5$ billion, and the estimated total cost of the burden was $\$ 98.9$ billion, $6 \%$ of the gross domestic product (AIHW 2016; RANZCP 2016).

Hospital emergency departments (EDs) are frequently the first point of contact for individuals seeking mental health services, accounting for $3.4 \%$ of ED visits in public hospitals (AIHW 2016). However, this is expensive and generally unnecessary; in 2014-2015 the majority (60.7\%) of mental health ED visits were resolved without the need for admission. In addition to EDs, mental illness is frequently treated in general practice (GP). In Australia in 2014-2015, an estimated $12.7 \%$ of GP visits were due to mental health-related issues, primarily depression, including 2.9 million government-supported services (AIHW 2016; Britt et al. 2015). This rate is increasing by approximately $6.1 \%$ annually since 2010, placing pressure on GP resources (Britt et al. 2015). The most common course of treatment is medication which does not target the range of biopsychosocial factors that contribute to mental illness and does not produce the most effective long-term outcomes (Britt et al. 2015; Davey 2008).

The limitations and expense of EDs and GPs treating mental illness is recognised in Australian health policy which aims to increase the services provided in the community (AHMAC 2013). The strategy is recovery-oriented and promotes evidence-based services that provide biopsychosocial support. Additionally, the strategy aims to embrace new models of community care (AHMAC 2013). An approach which is well suited to the current Australian mental illness service strategy and addresses the current population needs is social prescribing. Social prescribing has a focus on community development, community capacity-building and creating social capital, and has the potential to address the individual and societal impacts of mental illness by improving Quality of Life (QoL) and decreasing burden (Knapp et al. 2012).

Social prescribing programs can be broadly focussed, for example the Expert Patients Program, where participants attended self-management groups to improve self-efficacy, confidence, and QoL (Rogers et al. 2008). Group education included exercise, meal planning, symptom management, relaxation techniques, and partnering and communicating with physicians. Participants demonstrated improved perceived physical health, QoL, health self-efficacy, and reduced healthcare utilisation and costs (Rogers et al. 2008). Similar broadly-focussed programs can involve casemanagement and referral to a range of community-based services, including parent groups, disease-specific support groups, alcohol and drug support groups, and welfare advice (Grant et al. 2000; Kimberlee et al. 2014; Windle et al. 2009). Further, more targeted initiatives involve specific group activities such as bush walking and horticulture, community group exercise, arts and crafts, and time-banking (Bragg et al. 2013; Burgess 2014; Potter 2015; Stirrat 2014).

In terms of physical health, social prescribing programs demonstrate efficacy in improving overall self-reported health status, increased physical activity, and improved energy and fatigue (Bragg et al. 2013; Druss et al. 2010; Kimberlee et al. 2014; Lorig et al. 2001). Social prescribing can also improve psychological health, including QoL and wellbeing, depression and anxiety, mood disturbance and anger, and health self-efficacy (Bragg et al. 2013; Lorig et al. 2001; Potter 2015; Rogers et al. 2008). Social prescribing studies demonstrate efficacy in improving social participation including community participation and improved social support (Bragg et al. 2013; Burgess 2014; Potter 2015), and economic participation by increasing rates of employment and mean household income (Burgess 2014; Kimberlee et al. 2014).

In terms of burden on the health system, social prescribing can decrease the number of hospital admissions, outpatient visits, mean length of hospital stay, number of GP visits, allied health appointments and prescription medication usage (Kimberlee et al. 2014; Loughren et al. 2014; Rogers et al. 2008; Windle et al. 2009). The financial impact of these savings is also demonstrated (Kimberlee et al. 2014; Windle et al. 2009). A meta-analysis of social prescribing studies by Knapp et al. (2012) concluded that relatively lowcost investments in community capital-building initiatives can result in sizeable public savings.

Social prescribing programs have not been widely implemented, nor evaluated, in Australia. A not-for-profit nongovernment organisation that delivers community-focussed health care, developed and implemented Australia's first social prescribing program for mental illness, the Plus Social program. Participants diagnosed with mental illness living in the community under the care of a GP, were assessed by a social worker, and referred to appropriate locally-based health and welfare services and social activities. The program aimed to improve QoL and wellbeing, health selfefficacy, and social and economic participation.

This paper reports on the evaluation of the Plus Social program. The primary objective of this study was to evaluate whether the pilot program improved QoL, and social and economic participation. The research questions informing the evaluation were: (1) can a Plus Social program improve QoL including psychological wellbeing, physical health, welfare needs, loneliness and self-efficacy; and (2) can a Plus Social program improve social and economic participation?

\section{Methods}

A pre-post analysis of de-identified data was undertaken. 


\section{Design}

Evaluation of the pilot program used an exploratory, quantitative, longitudinal design. Data were collected pre-intervention (baseline) and at six months (follow-up).

\section{Participants}

Participants were required to be aged $18-65$ years, living in the community in the Sydney Local Health District, and diagnosed with serious mental illness likely to last 6 months or longer. Serious mental illness is one that is severe and persistent, with complex needs - a "mental, behavioural, or emotional disorder resulting in serious functional impairment, which substantially interferes with or limits one or more major life activities" (NIMH 2019).

Potential participants were excluded if they were receiving current acute inpatient treatment or had a significant cognitive impairment.

Participants were patients who self-presented to their GP and were referred into the Plus Social program if the GP determined they met the inclusion criteria, had unmet biopsychosocial needs, and were likely to benefit from inclusion in the program. Participants were offered enrolment in the study by their GP.

\section{Procedures}

Participants were assessed in their home by a mental health social worker; social workers completed all tools by reading questions aloud to participants, with the exception of the welfare needs and support assessment (Camberwell Assessment of Need Short Appraisal Schedule; Slade et al. 1999) which the social workers completed based on their own assessment of participant needs. Baseline data collection comprised assessment of participant wellbeing and welfare needs to inform referral to services. Link workers discussed potential services with participants and provided service information and referrals. Services included the Connecting Care Chronic Disease Management Program, the NSW Health Housing and Accommodation Support Initiative, the Personal Helpers and Mentors service, and the Acute PostAcute Care 'Hospital in the Home' service (ACI 2014; DSS 2013; Muir 2007; NSLHD 2015).

All participants attended a weekly arts and crafts group (2-3 h for 10 weeks); groups were led by a practicing artist/instructor and co-facilitated by a mental health social worker who maintained communication with participants throughout the program, and provided additional supports and adjustments pre- and post-activities, for example arrangements for transportation. All participants received ongoing support and review both from their GP and social worker throughout the program.

\section{Materials}

\section{Quality of Life}

The World Health Organisation QoL tool WHOQoL measured overall QoL (1 item) and health satisfaction (1 item), and four domains including physical health, psychological health, social relationships, and environment. Higher scores indicated greater perceived QoL and health satisfaction (WHOQoL Group 1998).

\section{Welfare Needs and Support}

The Camberwell Assessment of Need Short Appraisal Schedule CANSAS measured health and welfare needs including accommodation, food, financial, physical, psychological, and social needs. Needs rated as "Met", "Unmet", or "No Problem" (Slade et al. 1999).

\section{Health Status and Health Self-efficacy}

The EuroQol Health Thermometer EQ5D measured perceived health state on a visual analogue scale from 0 'worst imaginable health state' to 100 'best imaginable health state'. One item assessed health self-efficacy: "I am confident in my ability to take action when my health status changes", rated 1 (strongly disagree) to 5 (strongly agree) (Herdman et al. 2011).

\section{Psychosocial Distress}

The Kessler Psychological Distress Scale K10 measured global psychosocial distress including agitation, fatigue, and depression in the past four weeks. Higher scores indicate greater distress (AMHOCN 2005; Kessler et al. 2002).

\section{Loneliness and Social Participation}

The UCLA 3-item Loneliness Scale measured how frequently participants feel left out, isolated, or lacking companionship. Higher scores indicate greater loneliness. One item assessed frequency of social participation in the previous two weeks, rated 1 (never) to 4 (frequently) (Hughes et al. 2004).

\section{Economic Participation}

One item measured participation in paid employment (yes/ no) in the previous 2 weeks. 


\section{Hospital Admissions}

One item measured number of hospital admissions (for any reason) in the previous 6 months. Note that due to small sample sizes and low incidence, this measure is not reported in the findings.

\section{Data Analysis}

Data were entered, cleaned, checked, and analysed in SPSS 22 (IBM 2013). Data were checked for normality and analysed per distribution characteristics. Within and betweengroup analysis was conducted, and significant differences considered when $p<0.05$. Within-group differences across time (changes in participant wellbeing, and social and economic participation) were analysed using Dependent $t$-tests and Wilcoxon signed-rank tests for non-parametric data. Between-group differences (variables related to participant retention and attrition) were analysed using independent $t$-tests, Mann Whitney $\mathrm{U}$ tests for non-parametric data, and Chi-Squared tests for categorical data. As the program was a pilot, the study was exploratory in nature and the probability of Type I errors arising due to multiple comparisons was not considered a major concern. As such, we did not do any corrections for multiple comparisons. For the same reasons we did not use intention-to-treat to account for attrition. We wanted to examine all comparisons to determine if statistical significance demonstrated important clinically meaningful associations.

Ethical approval was granted by The Southern Cross University HREC (2016/560). Author CA has received research grants from Primary and Community Care Services, and author JBa is the CEO of Primary and Community Care Services, NSW, Australia. All authors certify responsibility for the manuscript.

\section{Results}

\section{Participant Characteristics}

Twenty-four participants commenced the program and 11 were lost to follow-up (54\% retention). The final sample included 13 participants ( $n=9$ female, $69 \%$ ) with an average age of 45 years $(S D=15)$.For participants who completed the program, the most common primary diagnoses were depression $(n=3)$ and anxiety $(n=3)$, and most common problems were anxiety $(n=2)$, stress $(n=2)$, and sleep disturbance $(n=2)$. In terms of participants who withdrew from the program, the most common primary diagnosis was bipolar disorder $(n=4)$; all of these participants withdrew $(100 \%$ attrition). The most common severe disorder for participants who withdrew from the study was anxiety $(n=4)$. There were no significant demographic differences (all $p>0.05$ ) between participants who did or did not withdraw.

\section{Biopsychosocial Wellbeing}

Participant's scores for all questionnaires with testing of change from baseline to follow-up outlines below. Means for baseline $\left(M_{B}\right)$ and follow-up $\left(M_{F}\right)$ are presented with degrees of freedom following in parentheses.

\section{Quality of Life (WHO-QoL)}

Self-report overall health satisfaction $\left(M_{B}=2.4(1.00)\right.$, $\left.M_{F}=3.3(0.97), t(10)=3.194, p<0.05\right)$, physical QoL $\left(M_{B}=11.6(1.78), M_{F}=13(3.620), t(10)=2.451, p<0.05\right)$, and psychological QoL $\left(M_{B}=10.3(2.45), M_{F}=12.4(2.96)\right.$, $t(10)=2.909, p<0.05)$ improved significantly from pre- to post-intervention. However, overall QoL $\left(M_{B}=3.3(0.45)\right.$, $\left.M_{F}=3.5(0.90), t(10)=1.305, p=0.221\right)$, social relationships $\left(M_{B}=12.3(3.63), M_{F}=12.9(4.24), t(10)=1.041, p=0.322\right)$, and environment QoL $\left(M_{B}=14.4(2.67), M_{F}=14.8(3.21)\right.$, $t(10)=1.44, p=0.18)$ did not improve significantly.

\section{Welfare Needs and Support (CANSAS)}

Both met $\left(M_{B}=5.0(2.48), M_{F}=5.5(3.53), t(10)=0.268\right.$, $p=0.794)$ and unmet $\left(M_{B}=3.8(1.21), M_{F}=5.5(5.57)\right.$, $t(10)=1.025, p=0.33$ ) health and welfare needs (e.g. accommodation, food, financial, physical, psychological and social needs) tended to increase, however there were no significant changes.

\section{Health Status (EQ5D) and Health Self-efficacy}

Self-report health status improved significantly from preto post-intervention $\left(M_{B}=59.1(18.68), M_{F}=71.7(14.82)\right.$, $t(9)=2.964, p<0.05)$. Health self-efficacy was moderately high over the course of the study, and did not change significantly from pre- to post-intervention $\left(M_{B}=3.6(1.26)\right.$, $\left.M_{F}=3.7(0.78), t(11)=0, p=1\right)$.

\section{Psychological Distress (K10)}

Overall psychological wellbeing was moderate-high (Andrews and Slade 2001) over the course of the study, and a despite a trend towards improving psychological wellbeing there were no significant differences in distress from pre- to post-intervention $\left(M_{B}=25.3(9.38), M_{F}=22.8(8.23)\right.$, $t(11)=1.145, p=0.277)$. 


\section{Loneliness (UCLA 3-Item Loneliness Scale) and Social Participation}

There were no significant differences in self-rated loneliness from pre- to post-intervention $\left(M_{B}=6.4(2.29)\right.$, $\left.M_{F}=6.1(2.17), t(10)=0.412, p=0.689\right)$, however scores trended downwards indicting participants experienced less loneliness over the course of the study. There were no significant differences in social participation from pre- to postintervention $\left(M_{B}=2.7(1.32), M_{F}=2.9(0.94), t(10)=0.232\right.$, $p=0.821)$.

\section{Economic Participation}

Participant economic participation was low across the study. At baseline three participants (23\%) reported economic participation in the previous 2 weeks, and this decreased to one participant (8\%) at follow-up; Wilcoxon Signed-Rank $Z=1$, $p=0.317$.

\section{Discussion}

This pilot study aimed to evaluate the Plus Social program, a social prescribing program for mental illness, implemented in Sydney, Australia. The primary study objective was to evaluate whether the program improved QoL, and social and economic participation. Participants who completed the program experienced significant improvement in physical and psychological QoL, health satisfaction and self-perceived health status. There were no significant differences in social participation and self-rated loneliness, although scores indicated participants experienced less loneliness over the course of the study, and economic participation remained low.

Patients who reported improvement in self-perceived health status experience increased independence and improvement in their perceived ability to self-managed their health/mental health conditions (Bragg et al. 2013). Previous findings reported in the grey literature suggest that patients accessing similar programs have higher levels of satisfaction with the support they receive and feel better supported to manage their condition (Dayson and Bashir 2014).

Health self-efficacy was moderately high over the study duration and did not improve significantly from pre- to postintervention. This finding may be due to the nature of the sample, whereby participants were required to independently present to a GP and consent to participation in the program, and thus may have had generally high health self-efficacy. Additionally, it may be due to the focus of the program. For example, the Expert Patients Program primarily targeted health self-efficacy; the goal of the intervention was to "reinforce the value and salience of people's pre-existing self-care activities, rather than initiating alternative behavioural changes" (Rogers et al. 2008, p. iii). Post-intervention, participants reported significantly improved self-efficacy, significantly better QoL, and lower service utilisation (e.g. fewer GP practitioner visits) (Rogers et al. 2008). Whilst the current study also improved QoL and resources utilisation, the mechanism of change was focussed on behaviours, and thus possibly not mediated by self-efficacy, resulting in a non-significant change.

Social prescribing has a focus on community development, community capacity-building and creating social capital, and has the potential to address the individual and societal impacts of mental illness by improving QoL and decreasing the burden of mental illness (Knapp et al. 2012). International social prescribing programs have reported direct economic health-related resource and cost benefits, reducing financial burden on the health system (Loughren et al. 2014).

In terms of scalability, social prescribing utilises existing services and is easy to implement as linkages between potential participants and their GP (point of identification/ recruitment) already exist (Rogers et al. 2008). Additionally, social prescribing can target minority groups (as these support groups frequently already exist), and individuals facing disadvantage (with linkages to free, local services). Existing grey literature suggests that whilst health care professionals may be beneficial in terms of creating positive psychological and physical health gains and the ability to self-manage, volunteers could provide group facilitation to improve long term connectivity (Dayson and Bashir 2014). This pilot program demonstrated the potential efficacy of social prescribing in the Australian context. Social prescribing fits well within Australian health policy which focusses on bolstering community care; could easily be included in the current Primary Health Network funding model; and may be scalable to the Australian context, including geographically isolated communities.

\section{Limitations}

While a strength of this pilot study was the use of validated tools for data collection, there are some clear limitations. Findings are only generalisable to a Sydney Local Health District in Australia, as the small sample size was likely to impact on external validity. Further impacting sample size was a high loss to follow-up ( $46 \%$ drop out rate), however, there were no other significant demographic differences between participants who did or did not withdraw; no further differences between these groups were explored. It is unclear whether the low participation rates were due to the mental health of the patients, the program, or something else; for example, the most common severe disorder for participants who withdrew from the study was anxiety which may have 
directly impacted retention. All participants diagnosed with bipolar disorder withdrew from the study, which is consistent with previous research indicating high attrition rates in this group (Moon et al. 2012). Only two retained participants were diagnosed with a psychotic spectrum disorders; unfortunately, psychotic symptoms were not assessed which may have further elucidated this finding. Future research could consider alternative retention strategies for these groups; in particular, qualitative interviews may elucidate strategies for retention, as may psychoeducation regarding adherence (Moon et al. 2012). We were also unable to establish the number and diagnosis of those who declined to participate in the study which represents a selection bias and may have skewed the results in favour of better functioning individuals. Despite the limitations of the pilot study in terms of power and generalizability, it is encouraging that participants did demonstrate improvements in QoL, however future studies with larger samples and improved selection techniques are needed to validate these findings.

An additional limitation was a lack of long-term followup of participants, which is not uncommon in this type of study, and should be considered in future research (Bickerdike et al. 2017). For example, at twelve months following the Wellspring Healthy Living Centre's Wellbeing program, $29 \%$ of beneficiaries obtained employment. Additionally, participants reported significantly fewer GP visits, significantly shorter GP visits, and a decline of $14 \%$ in medication prescriptions (Kimberlee et al. 2014). Therefore, longer follow-up periods could allow further insight into the social and financial outcomes of social prescribing programs.

\section{Implications for Behavioral Health}

The results from this pilot program are promising; there were significant improvements in a range of biopsychosocial health and economic outcomes, suggesting that social prescribing would be an appropriate intervention in Australian settings. Use of volunteers for group facilitation to improve long-term social connectivity in future research is also recommended.

Author contributions JBa developed and implemented the social prescribing program and provided the data for analysis. TT conducted data analysis, CA, TT, CG, and JBl produced this manuscript. All authors read and approved the final manuscript.

Funding This study was funded by Primary and Community Care Services, NSW, Australia.

Data Availability The datasets supporting the conclusions of this article are available from the corresponding author upon request.

\section{Compliance with Ethical Standards}

Conflict of interest Author CA has received research grants from Primary and Community Care Services, NSW, Australia. Author JBa is the CEO of Primary and Community Care Services, NSW, Australia.

Ethics Approval Ethical approval was granted by The Southern Cross University HREC (2016/560); all procedures were in accordance with the HREC standards and the 1964 Helsinki declaration and its later amendments. De-identified data from an existing dataset were provided for analysis by Primary and Community Care Services, NSW, Australia; for this type of study formal consent is not required.

Informed Consent De-identified data from an existing dataset were provided for analysis by Primary and Community Care Services, NSW, Australia; for this type of study formal consent is not required.

Open Access This article is licensed under a Creative Commons Attribution 4.0 International License, which permits use, sharing, adaptation, distribution and reproduction in any medium or format, as long as you give appropriate credit to the original author(s) and the source, provide a link to the Creative Commons licence, and indicate if changes were made. The images or other third party material in this article are included in the article's Creative Commons licence, unless indicated otherwise in a credit line to the material. If material is not included in the article's Creative Commons licence and your intended use is not permitted by statutory regulation or exceeds the permitted use, you will need to obtain permission directly from the copyright holder. To view a copy of this licence, visit http://creativecommons.org/licenses/by/4.0/.

\section{References}

Agency for Clinical Innovation. (2014). State-wide evaluation: NSW Chronic Disease Management Program, final report. Newtown, Australia: George Institute for Global Health. Retrieved May 11, 2020, from https://www.health.nsw.gov.au/cdm/Documents/ CDMP-Evaluation-Report-2014.pdf.

Andrews, G., \& Slade, T. (2001). Interpreting scores on the Kessler psychological distress scale. Australian and New Zealand Journal of Public Health, 25(6), 494-497. https://doi.org/10.1111/j.1467842X.2001.tb00310.x.

Australian Bureau of Statistics. (2008). National survey of mental health and wellbeing: Summary of results, Australia, 2007 [4326.0]. Retrieved May 11, 2020, from https://www.abs.gov.au/ ausstats/abs@.nsf/mf/4326.0.

Australian Health Ministers' Advisory Council. (2013). A national framework for recovery-oriented mental health services. Canberra: Department of Health, Commonwealth of Australia. Retrieved May 11, 2020, from https://www1.health.gov.au/inter net/main/publishing.nsf/Content/mental-pubs-n-recovfra.

Australian Institute of Health and Welfare. (2016). Australia's health 2016 [Cat. no. AUS 199]. Canberra, Australia: AIHW. Retrieved May 11, 2020, from https://www.aihw.gov.au/getmedia/9844cefb7745-4dd8-9ee2-f4d1c3d6a727/19787-AH16.pdf.aspx.

Australian Mental Health Outcomes and Classification Network. (2005). Kessler-10 training manual. Parramatta, Australia: NSW Institute of Psychiatry. Retrieved May 11, 2020, from https:// www.amhocn.org/publications/kessler-10-training-manual-andslides.

Bickerdike, L., Booth, A., Wilson, P. M., Farley, K., \& Wright, K. (2017). Social prescribing: Less rhetoric and more reality. A 
systematic review of the evidence. British Medical Journal Open, 7(4), e013384. https://doi.org/10.1136/bmjopen-2016-013384.

Bragg, R., Wood, C., \& Barton, J. (2013). Ecominds: Effects on mental wellbeing. London, UK: Mind. Retrieved May 11, 2020, from https://www.mind.org.uk/media/354166/Ecominds-effects-onmental-wellbeingevaluation-report.pdf.

Britt, H., Miller, G., Henderson, J., Bayram, C., Harrison, C., Valenti, L., et al. (2015). General practice activity in Australia 2014-15. Sydney: Sydney University Press.

Burgess, G. (2014). Evaluation of the Cambridgeshire timebanks. Cambridge: Cambridge Centre for Housing and Planning Research.

Davey, G. (2008). Psychopathology: Research, assessment and treatment in clinical psychology. Chichester, UK: Wiley.

Dayson, C., \& Bashir, N. (2014). The social and economic impact of the Rotherham Social Prescribing Pilot: Main evaluation report. Rotherham/Sheffield, UK: Voluntary Action Rotherham and Centre for Regional Economic and Social Research.

Department of Social Services. (2013). Targeted Community Care (Mental Health) Program - Personal Helpers and Mentors (PHaMs). Canberra: Australian Government. Retrieved May 11, 2020, from https://www.ideas.org.au/uploads/resources/628/Perso nal $\% 20$ Helpers $\% 20$ and $\% 20$ Mentors.pdf.

Druss, B. G., Silke, A., Compton, M. T., Rask, K. J., Zhao, L., \& Parker, R. M. (2010). The Primary Care Access Referral, and Evaluation (PCARE) study: A randomized trial of medical care management for community mental health settings. The American Journal of Psychiatry, 167(2), 151-159. https://doi.org/10.1176/ appi.ajp.2009.09050691.

Grant, C., Goodenough, T., Harvey, I., \& Hine, C. (2000). A randomised controlled trial and economic evaluation of a referrals facilitator between primary care and the voluntary sector. $B M J$, 320(7232), 419-423. https://doi.org/10.1136/bmj.320.7232.419.

Herdman, M., Gudex, C., Lloyd, A., Janssen, M. F., Kind, P., Parkin, D., et al. (2011). Development and preliminary testing of the new five-level version of EQ-5D (EQ-5D-5L). Quality of Life Research, 20(10), 1727-1736. https://doi.org/10.1007/s1113 6-011-9903-x.

Hughes, M. E., Waite, L. J., Hawkley, L. C., \& Cacioppo, J. T. (2004). A short scale for measuring loneliness in large surveys: Results from two population-based studies. Research on Aging, 26(6), 655-672. https://doi.org/10.1177/0164027504268574.

IBM. (2013). SPSS Statistics for Windows, Version 22.0 [computer program]. Armonk, NY: IBM Corp.

Kessler, R. C., Andrews, G., Colpe, L. J., Hiripi, E., Mroczek, D. K., Normand, S. L., et al. (2002). Short screening scales to monitor population prevalences and trends in non-specific psychological distress. Psychological Medicine, 32(6), 959-976. https://doi. org/10.1017/S0033291702006074.

Kimberlee, R., Ward, R., Jones, M., \& Powell, J. (2014). Measuring the economic impact of Wellspring Health Living Centre's Social Prescribing Wellbeing Programme for low level mental health issues encountered by GP services. Bristol, UK: Wellspring.

Knapp, M., Bauer, A., Perkins, M., \& Snell, T. (2012). Building community capital in social care: Is there an economic case? Community Development Journal, 48(2), 313-331. https://doi. org/10.1093/cdj/bss021.

Lorig, K. R., Ritter, P., Stewart, A. L., Sobel, D. S., Brown, B. W., Jr., Bandura, A., et al. (2001). Chronic disease self-management program: 2-year health status and health care utilization outcomes. Medical Care, 39(11), 1217-1223.

Loughren, E. A., Matthews, J., Baker, C., Speke, C., \& Crone, D. (2014). Artlift Gloucestershire Update Report 2011-2014.
Gloucestershire, UK: University of Gloucestershire. Retrieved May 11, 2020, from http://eprints.glos.ac.uk/2376/.

Moon, E., Chang, J. S., Kim, M. Y., Seo, M. H., Cha, B., Ha, T. H., et al. (2012). Dropout rate and associated factors in patients with bipolar disorders. Journal of Affective Disorders, 141(1), 47-54.

Muir, K. (2007). Housing and Accommodation Support Initiative (HASI): Stage 1 evaluation report. Sydney, Australia: Social Policy Research Centre, University of New South Wales. Retrieved May 11, 2020, from https://www.cadr.org.au/search-clearingho use/clearing-house/housing-and-accommodation-support-initi ative-hasi-stage-1-evaluation-report.

National Institute of Mental Health. (2019). Mental Illness. Bethesda, USA. NIMH, National Institutes of Health. Retrieved May 11, 2020, from https://www.nih.gov/about-nih/what-we-do/nih-alman ac/national-institute-mental-health-nimh.

Northern Sydney Local Health District. (2015). APAC Acute-Post Acute Care Hospital in the Home. St Leonards, Australia: NSLHD, NSW Health. Retrieved May 11, 2020, from https://www.nslhd .health.nsw.gov.au/Services/Directory/Pages/APAC.aspx.

Potter, S. (2015). Arts on Prescription 2014-15 evaluation report. Cambridge, UK: Arts and Minds. Retrieved May 11, 2020, from https://artsandminds.org.uk/artsandm/wp-content/uploa ds/2015/10/arts-on-prescription-2014_15_evaluation-report_draft .pdf.

Rogers, A., Kennedy, A., Bower, P., Gardner, C., Gately, C., Lee, V., et al. (2008). The United Kingdom Expert Patients Programme: Results and implications from a national evaluation. Medical Journal of Australia, 189, S21-S24. https://doi. org/10.5694/j.1326-5377.2008.tb02205.x.

Royal Australian \& New Zealand College of Psychiatrists. (2016). The economic cost of serious mental illness and comorbidities in Australia and New Zealand. Melbourne, Australia: RANZCP. Retrieved May 11, 2020, from https://www.ranzcp.org/files/resou rces/reports/ranzcp-serious-mental-illness.aspx.

Slade, M., Thornicroft, G., Loftus, S., Phelan, M., \& Wykes, T. (1999). CAN: Camberwell assessment of need. London: Gaskell.

Stirrat S. (2014). An evaluation of the Green Prescription Programme in Co. Donegal, Master's Thesis. Sligo, Ireland: Institute of Technology Sligo. Retreived from https://research.thea.ie/bitstream/ handle/20.500.12065/1424/An\%20Evaluation\%20of\%20the $\% 20$ Green $\% 20$ Prescription $\% 20$ Programme $\% 20$ in $\% 20$ Co. $\% 20$ Donegal $\% 20$ By $\% 20$ Siofra\%20Stirrat $\% 20 \% 28 \mathrm{MSc} \% 20$ Thesis $\% 29$. pdf?.

Windle, K., Wagland, R., Forder, J., D’Amico, F., Janssen, D., \& Wistow, G. (2009). National evaluation of Partnerships for Older People projects. London, UK: Personal Social Services Research Unit. Retrieved May 11, 2020, from https://www.pssru.ac.uk/pub/ dp2700.pdf.

World Health Organization. (2005). Promoting mental health: Concepts, emerging evidence, practice. Retrieved May 11, 2020, from https://www.who.int/mental_health/evidence/en/promoting_mhh. pdf.

WHOQoL Group. (1998). Development of the World Health Organization WHOQOL-BREF quality of life assessment. Psychological Medicine, 28(3), 551-558. https://doi.org/10.1017/S003329179 $8006667 \mathrm{P}$.

Publisher's Note Springer Nature remains neutral with regard to jurisdictional claims in published maps and institutional affiliations. 